phils and histiocytes. ${ }^{6}$ The mechanism of the reaction is unknown.

The frequency with which treatment with some drugs has been accompanied by the development of a syndrome resembling systemic lupus erythematosus suggests a causal relationship. $^{7}$ In one series the disease was thought to be druginduced in $20 \%$ of cases. ${ }^{8}$ Drugs which have been held to be the cause of it include penicillin, tetracycline, gold, phenylbutazone, griseofulvin, hydrallazine, isoniazid, carbamazepine, phenytoin, mephenytoin, streptomycin, procainamide, sulphonamides, para-aminosalicylic acid, thiouracils, trimethadione, guanoxan, methsuximide, and methyldopa. Respiratory disease in systemic lupus erythematosus may present with pleurisy, often with effusion, sometimes with pericarditis in addition. Alternatively symptoms may be associated with a clinical illness resembling pneumonia, pulmonary oedema, or infarction. Another type of pulmonary disease results in shrinking lungs, in which there is progressive elevation of the diaphragm and dyspnoea. These changes are due to widespread alveolar atelectasis without airway obstruction. ${ }^{9}$

Drugs have been reported as precipitating some cases of polyarteritis nodosa. ${ }^{10}$ These include iodides, organic arsenicals, mercurials, hydantoins, penicillin, gold salts, dicophane (D.D.T.), thiouracils, phenothiazines, and sulphonamides. Polyarteritis may present as a disorder of the respiratory system, with asthma, transient lung shadows, or destructive lung lesions resembling pneumonia, lung abscess, or infarction.

Any iodine-containing compound, however administered, may result in iodism. Symptoms may be immediate or delayed by many days. The respiratory tract may be involved diffusely with tracheobronchitis, asthma, or pneumonia, or focally by angioneurotic oedema or haemorrhage. The mechanism of iodism is unestablished.

The use of ganglion-blocking hypotensive agents, hexamethonium, pentolinium, and mecamylamine, has been associated with intra-alveolar fibrinous oedema, which in some cases becomes converted into fibrous tissue. Whether these changes are directly due to the drugs or to left ventricular failure is controversial. ${ }^{11}$ The clinical picture of the acute stage is that of pulmonary oedema. Fibrosis may develop and become widespread, leading to honeycomb lung, bronchiolectasis, and bronchiectasis. ${ }^{12}$ Busulphan, a cytotoxic drug chemically related to hexamethonium, may also cause intraalveolar fibrinous oedema converting to fibrous tissue. ${ }^{13}$ The drug also induces widespread cellular changes throughout the body. Damage to the alveolar cells responsible for the production of surfactant may be the cause of the intra-alveolar oedema.

Pulmonary embolism is a well-recognized hazard of some oral contraceptives. Oil embolism has followed lympangiography with oil medium when the oil is returned to the venous system. It has occurred after oil-containing contrast medium has been inadvertently injected into the vein during hysterosalpingography, myelography, and urethrography. ${ }^{14}$

Prolonged ventilation with high concentrations of oxygen may result in lung disease, the microscopical features of which show two merging phases. An early exudative phase is characterized by congestion, alveolar oedema, intra-alveolar haemorrhage, and fibrin exudates, with the formation of prominent hyaline membrane without an associated inflammatory component. A late proliferative phase shows alveolar and interlobular septal oedema and fibroblastic proliferation, with early fibrosis and prominent hyperplasia of the alveolar lining-cells. These changes seem likely to be due to the prolonged inspiration of high partial pressures of oxygen. ${ }^{15}$ Oxygen should not be withheld from patients who need it for fear of possible toxic effect on the lungs, but the concentration should be reduced to $40 \%$ or less as soon as measurements of arterial blood gas show that this can be done safely.

\section{Leprosy in England}

Leprosy is in the news again. Alarmist reports of an " outbreak" in Leicester have been followed by a spate of emotional comments, exaggerated fears, and ill-considered references to "Whitehall secrecy" and uncontrolled immigration.

What are the facts? From 1951 (when leprosy was made a notifiable disease) to the end of 1968 a total of 777 patients had been registered in England and Wales, 45 of them in 1968. After deduction of the numbers of patients in whom the disease was definitively arrested, or who had returned to their homeland, or had died, 355 remained on the register, of whom 171 were considered to require treatment for active leprosy. So far this year some 22 patients have been notified in the whole country. About one in 10 of those with active leprosy are at present being treated as inpatients. Statistics have been published in the annual reports of the Chief Medical Officer to the Ministry (now Department) of ${ }_{3}$ Health. From time to time up-to-date figures are supplied by Government spokesmen in the House of Commons in reply to Parliamentary questions. ${ }^{1-3}$

The total of 22 patients notified in the Leicester district since 1951 should be seen in the light not only of the presence of a large population that has in the past been exposed to the risk of leprosy but also of a commendable awareness of leprosy on the part of Leicester general practitioners and dermatologists.

Nobody has contracted leprosy in Britain since the disease was made notifiable, and only three people have been reliably reported to have caught leprosy here this century, the last instance being over 40 years ago. ${ }^{45}$ Endemic leprosy disappeared from the British Isles in 1798, and the subsequent intermittent trickle of imported cases (precise numbers before 1951 are unknown) has included devoted missionaries, professional and service personnel, and others. It is since the second world war that the influx of immigrants has accentuated the problem, because many of them have been exposed to leprosy (as to other exotic diseases) in their countries of origin. ${ }^{6}$ The maintenance of the level of cases notified each year since 1962 is due to several factors-namely, the long " silent" or incubation period of leprosy, a greater awareness of leprosy on the part of doctors generally, the increasing readiness of patients to come forward, and sometimes the growing difficulty of concealing the more obvious signs of leprosy or its neurological sequelae.

It is possible that in conditions of gross overcrowding (the only major established factor of epidemiological importance) a few isolated cases of leprosy may arise within the next few years among close contacts of known or unknown patients. But in the generally prevailing standards of hygiene it is highly unlikely that leprosy could ever become established in Britain or that the risk to any inhabitant could be greater 
than one in millions. In this country, as elsewhere, some persons suffering from leprosy may have not yet been diagnosed. In addition, there are certainly some who are in the symptomless "silent" phase of the disease, which is undetectable by any means at present available. Nothing is known with certainty about healthy carriers of leprosy bacilli.

Much of the criticism of "Whitehall secrecy" is directed towards the advice given to medical officers of health that they should maintain strict confidentiality regarding all persons suffering from leprosy and avoid reference to it in their weekly statistical return to the General Register Office. The confidentiality is necessary in the interest of the patients as well as of the community. ${ }^{7}$ The smaller the locality in which information about the number of leprosy patients is made public, the greater the chance that the individual patient will be identified by some irresponsible person. And identification, even in Britain in 1969, may, because public fear of leprosy is greatly exaggerated, result in grave distress to the patient and his family. Leprosy is one of the least contagious of the communicable infections. Moreover, even in conditions predisposing to transmission, the vast majority of persons living in this country would probably prove refractory to it. Only about $1 \%$ would develop progressive lepromatous leprosy, these persons being congenitally incapable of lysing Mycobacterium leprae. Any relaxation of confidentiality might result in concealment of the disease, particularly in its early, easily curable, and relatively noncontagious stage.

Not all persons suffering from leprosy can pass on the infection. In fact, those with indeterminate and tuberculoid leprosy may be regarded administratively as "closed"; scanty and non-viable Myco. leprae are found only after prolonged search of serial sections of skin. Patients with lepromatous or intermediate (borderline or dimorphous) leprosy are rendered non-contagious after a few months of treatment with standard drugs. The lesions themselves, like the non-viable bacillary debris, may take years to disappear, but the patient is no longer contagious. Deformity is no indication of activity of the disease, and the discharge from neuropathic ulceration of the extremities rarely contains viable leprosy bacilli. In general, the more obvious the lesions the less contagious the patient.

When a geographic history is taken, so important nowadays, ${ }^{8}$ southern Europe and the Mediterranean islands must be remembered as being within the endemic zone. Then leprosy must be thought of as a possible diagnosis in any atypical dermatosis, especially if non-irritating, and especially if it fails to respond to a standard treatment, and in any disorder of the peripheral nervous system. Prodromal symptoms may be suggestive, especially localized, recurrent, or persistent paraesthesiae. The earliest signs are usually some inconspicuous and symptomless changes in a localized area of skin. If in a hypopigmented skin lesion there is some sensory loss (to light touch, temperature, pain in that order) or impairment of sweating, the diagnosis is virtually certain. If in a suspected lesion there is no sensory impairment, a slit-smear

1 Hansard, 6 July 1965, col. 1158.

Hansard, 17 February 1966, col. 1674.

Leprosy Revievo, 1969, 40, 65

- MacLeod, J. M. H., British Medical fournal, 1925, 1, 107

- MacLeod, J. M. H., International fournal of Leprosy, 1935, 3, 67.

Jopling, W. H., London Clinic Medical fournal, 1963, 4, 47.

British Medical fournal, 1966, 1, 560.

- Maegraith, B. G., Lancet, 1963, 1, 401.

- Browne, S. G., British Medical Fournal, 1968, 3, 725.

- Browne, S. G., Leprosy in Britain, 68/22 (Medical Recording Service and Sound Library, Kitts Croft, Writtle, Chelmsford, Essex). 1968.

1 Whecler, E. A., Hamilton, E. G., and Harman, D. J., Leprosy Review, $1965,36,37$. preparation will generally show acid-fast organisms, perhaps in globi. Peripheral nerves at sites of predilection ${ }^{9}{ }^{10}$ are often enlarged, hard, and tender, even in the early stages. Examination of sections of skin, suitably stained, ${ }^{11}$ is confirmatory. (Past histopathological diagnoses of " sarcoidosis" should be critically reviewed, and pathognomonic lymphocytic infiltration of nerve fibrils sought.) The classical signs of the fully developed disease need no emphasis. The lepromin reaction is almost valueless as a diagnostic aid, however helpful it may be in prognosis and classification.

Close contacts should be examined every three months or so for several years. While the precise protective value of B.C.G. vaccination in leprosy is still a matter of dispute, some investigations suggest that it may enhance potential reactivity to mycobacterial antigen and hence protect up to $80 \%$ of exposed children ; so it should be offered to child contacts. Prophylactic dapsone need not be given in addition. Too many myths still surround this disease, and doctors have an educational task to allay the anxieties and apprehensions of the public.

\section{Ex-addict Hostel at Lewisham}

Last week the planning committee of Lewisham Borough Council gave permission to the Community Drug Project for a Victorian mansion, formerly a nurses' home, to become a hostel for 20 recovered narcotic addicts. These people will have been through hospital treatment and shown a sincere desire to co-operate. Planning permission was granted subject to review at the end of two years. The Ministry of Health in $1967^{1}$ recognized the need for special hostels to aid in the rehabilitation of heroin addicts, and the idea was endorsed in the 1969 report of the Advisory Committee on Drug Dependence. $^{23}$ But making the hostels a reality seems to have been hampered by difficulties over planning permission, though there are now several valuable schemes afoot for opening hostels outside London.

Lewisham's decision was courageous and made in the face of some local opposition. The opposers quoted paragraph 39 of the Advisory Committee's report on rehabilitation, ${ }^{1}$ claiming its recommendations had been that such hostels should not be sited in inner London but " in the outer suburbs or as much as twenty to thirty miles from London." On this basis it was claimed that the Home Office recommendations were being flouted and that the proposed siting constituted a serious threat to the neighbourhood. Pushers would be attracted, and the hostel residents (or relapsed ex-residents) would themselves introduce local children to drugs. The sponsors of the scheme gave as their reason for preferring an urban situation the argument that most young ex-addicts are by origin city dwellers, and therefore rehabilitation for them could not mean rustic pursuits. The sponsors also claimed that the hostel, as they planned to run it, posed no threat to the community.

\footnotetext{
${ }^{1}$ Ministry of Health Memorandum F/D121/11, 15 November 1967.

2 The Rehabiltation of Drug Addicts, Report of the Advisory Committee on Drug Dependence, Home Office. London, H.M.S.O. 1969.

- British Medical fournal, 1969, 2, 331.

- Rosenthal, M. S., in Scientific Basis of Drug Dependence, ed. H. Steinberg, p. 395. London, J. and A. Churchill. 1969.
} 